\title{
New skeleton from the early Oligocene of Germany indicates a stem-group position of diomedeoidid birds
}

Vanesa L. De Pietri, Jean-Pierre Berger, Claudius Pirkenseer, Laureline Scherler, and Gerald Mayr Acta Palaeontologica Polonica 55 (1), 2010: 23-34 doi: http://dx.doi.org/10.4202/app.2009.0069

We report a new specimen of the extinct procellariiform species Diomedeoides brodkorbi (Aves, Diomedeoididae) from the early Oligocene (Rupelian) of Rheinweiler in southwestern Germany. The well-preserved partial skeleton allows the recognition and reassessment of new osteological details that bear on the phylogenetic affinities of diomedeoidids. The presence on the coracoid of a deeply excavated, cup-like facies articularis for the scapula suggests a stem group position of the Diomedeoididae within Procellariiformes, because this trait also occurs in stem-group representatives of several avian groups, as well as in Mesozoic non-neornithine birds, and is a plesiomorphic character. We hypothesize that the similarities of Diomedeoides to extant southern storm-petrels (Oceanitinae), such as the long mandibular symphysis, the small processus supracondylaris dorsalis and the long legs are plesiomorphic for Procellariiformes.

Key words: Aves, Diomedeoididae, phylogeny, stem-group, Oligocene, Rupelian,Upper Rhine Graben, Germany.

Vanesa L. De Pietri [vanesa.depietri@nmbe.ch], Naturhistorisches Museum der Buergergemeinde Bern, Bernastrasse 15, CH-3005 Bern, Switzerland; Jean-Pierre Berger [jean-pierre.berger@unifr.ch], Claudius Pirkenseer [claudiusmarius.pirkenseer@unifr.ch], and Laureline Scherler [laureline.scherler@unifr.ch ], Dept. Geosciences-Earth Sciences, Chemin du Musée 6, University Fribourg, CH-1700 Fribourg, Switzerland; Gerald Mayr [Gerald.Mayr@ senckenberg.de], Forschungsinstitut Senckenberg, Sektion Ornithologie, Senckenberganlage 25, 60325 Frankfurt am Main, Germany. 
distribution, and reproduction in any medium, provided the original author and source are credited.

For Full text $(1,122.3 \mathrm{kB})$ 